\title{
A New Information System for Inventory Management in Hospitality Industry
}

\author{
Mune MOĞOL SEVER (D) a, Celal Hakan KAĞNICIOĞLU (iDb \\ a Faculty of Tourism, Department of Tourism Management, Anadolu University, Eskişehir, Turkey. \\ mmogol@anadolu.edu.tr \\ b Faculty of Economics and Administration Sciences, Department of Business, Anadolu University, Eskişehir, \\ Turkey. chkagnic@anadolu.edu.tr
}

\begin{tabular}{|c|c|}
\hline ARTICLE INFO & ABSTRACT \\
\hline $\begin{array}{l}\text { Keywords: } \\
\text { Inventory Mana }\end{array}$ & $\begin{array}{l}\text { Purpose - In this study, it is aimed to design an information system that will facilitate data and } \\
\text { inventory control, ordering and procurement and ensure the monitoring of material } \\
\text { consumption and cleaning process as a whole. }\end{array}$ \\
\hline $\begin{array}{l}\text { Material Requirements Plannin } \\
\text { (MRP) } \\
\text { Information System }\end{array}$ & $\begin{array}{l}\text { Design/methodology/approach - This study adopts case study on a sample of five-star hotel } \\
\text { chains. The study adopted the typical sampling. Data collection tools of the study are } \\
\text { observation, interviews and document analysis (procedures and forms). The ARIMA }(2,1,1)\end{array}$ \\
\hline Service Sector & $\begin{array}{l}\text { Model was utilized as the estimator in this study. The software is web-based, and uses SQL } 2008 \\
\text { R2 as database management system. Coding was performed in C \#. }\end{array}$ \\
\hline $\begin{array}{l}\text { Received } 15 \text { September } 2018 \\
\text { Revised } 19 \text { January } 2019 \\
\text { Accepted } 10 \text { February } 2019\end{array}$ & $\begin{array}{l}\text { Findings - As a result of the systems analysis, there is no reporting on the materials consumed. } \\
\text { Therefore, the information related to materials used per-unit or in total is not easily accessible } \\
\text { by employees. With the information system introduced in the scope of this study, periodical } \\
\text { planning be performed to ensure that demand-dependent material is delivered to the hotel and } \\
\text { the needs are met on time. }\end{array}$ \\
\hline $\begin{array}{l}\text { Article Classification: } \\
\text { Research Article }\end{array}$ & $\begin{array}{l}\text { Originality/value - Study, attempts to bridge the gap in this field especially by facilitating the } \\
\text { monitoring control off the relevant processes the processes in an integrated manner. It is } \\
\text { considered that the study will contribute to the literature since, although there are many studies } \\
\text { on MRP, there is a limited number of studies on the services sector and no studies especially on } \\
\text { hotels. }\end{array}$ \\
\hline
\end{tabular}

\section{INTRODUCTION}

Managers are having turmoil for data management due to the increase in material consumption in laborintensive sectors such as tourism. This fact forces managers to use management information systems that they can monitor more easily. Information systems are human-computer interactive systems that help managers in decision making (Turban \& Volonino, 2013). Information systems can often be designed for Material Requirement Planning (MRP) processes, just as they can be designed for any other decision-making processes.

MRP systems are computer-based systems that conduct inventory management. These systems are operated by making certain inputs and identifications in the system. Some of these inputs are product trees, inventory records and the master production schedule. After these inputs are done, the system makes backward scheduling starting from the delivery date. Procurement and order recommendations, schedule changes and job orders are obtained at the end of the operation (Stevenson, 2009).

When the package programs used at the hotels are examined, an integrated information system in which the materials that are specifically used in the cleaning process are systematically planned, the amounts of usage are automatically calculated and inventory monitoring can be carried out could not have been encountered. For this reason, this study aims to propose an information system which will dynamize the MRP in the process of cleaning services and support the decision making process in the hotels. Through this system, it is 
aimed to design an information system that will facilitate data and inventory control as well as ordering and purchasing and ensure the monitoring of material consumption and cleaning process as a whole.

It can be argued that empirical studies about MRP are generally concentrated on the manufacturing companies and conducted under certain titles. These titles include freezing the master production schedule (freezing), replanning (replanning), lot size policy determination (lot size policy), forecast error (forecast error) system restraint / tension / uncertainty, safety stock, uncertain demand, etc.(Andersson, Axs ÄTer, \& JÖNsson, 1981; Bai, Davis, Kanet, Cantrell, \& Patterson, 2002; Lee \& Adam, 1986; Lin \& Krajewski, 1992; Mula, Poler, \& Garcia-Sabater, 2008; Mula, Poler, \& Garcia, 2006; Segerstedt, 1996; Xie, Lee, \& Zhao, 2004; Yeung, Wong, \& Ma, 1998)

Another scholar classified the material management systems used in hospitals with the fuzzy clustering technique where the performance of the utilized system was compared based on the inventory turnover rate and inventory velocity criteria (Huarng, 1998). A similar study was conducted on the planning of the requirement for operating room textile materials. The system they developed consists of three modules: operation schedule, product trees for operations and inventory record information. In the linear programming they developed, the objective function is the minimization of the holding (inventory) cost (O'Neill, Murphy, Gray, \& Stoner, 2001). Considering hospitals job-shop type production plants, scholars suggested that MRP can be applied in hospitals and that the inventory could be reduced in this way (Sam, 1990; Showalter, 1987).

The significant part of the studies in this field is applied in the manufacture companies. This is due to the philosophy of MRP as to generating inputs to the master production schedule as well as MRP's association with the product concept (product trees etc.). In service companies, however, can be observed that the application is bounded by hospitals, the material planning system is far from the philosophy of MRP and material planning is generally associated with procurement in practice. It can be argued that no study has been found on MRP on the cleaning services of hotels where material traffic is intense.

Since the capacity constraints are not taken into account in the study, the problem was not capacitated; finished products are defined as multi product because they are more than one; and the independent demand is defined as single-level because it merely composes of single-level dependent products. In sum, the problem at hand was defined as an Uncapacitated Single Level, Single Item Multi Product Material Requirement Planning. In this study, an information system was designed to realize a MRP which is used in the cleaning process of the five-star hotel chains. . The prediction system that was developed in the model base makes weekly reservation forecasts. After the product trees related to the materials used for each room are formed and installed to the system, the software calculates the total amount of material requirements based on the estimated reservations. This software automatically calculates the inventory drops and consumption. The modules of the software are: Management, Operations and Reports. The information system is web-based and uses SQL 2008 R2 database management system. All coding was performed through the programs (C \#, ASPX and ASP) included in Visual Studio.

\section{METHOD}

\section{Data collection tools and sample selection}

This study adopts case study on a sample of five-star hotel chains. Case study is a type of qualitative research which consists of detailed exploration and analysis processes of the researcher seeking answers for 'why' and 'how' questions to understand and solve a problem (Johnston, Leach, \& Liu, 1999; Seale, Gobo, Gubrium, \& Silverman, 2004; Yin, 2002)In case studies, a single case is examined in depth. Results of studies can be generalized if correct sample is selected. This is an analytical generalization on the cases that bear the same properties (Seale et al., 2004; Yin, 2002). In other words, results of a case study can be transferred to other studies provided that their conclusions and models contain the same premises (Gomm, Hammersley, \& Foster, 2000; Seale et al., 2004; Yin, 2002). Thus, the results of a certain study gains validity in a wider field.

The study adopted the typical sampling which is a type of purposeful (judgmental) sampling. Typical sampling is defined as the selection of data sources that are expedient and contain rich data, as is the case in most purposeful sampling methods(Patton, 2002). If the hotel to be selected is a typical case that has 
corporate identity, has similar processes as other hotels, affiliated to a chain and is five-star, the model to be developed in the study can be generalized to other hotels with the same standards.

Data collection tools of the study are observation, interviews and document analysis (procedures and forms). Such a combination of multiple data-collection tools is called method triangulation (Bogdan E Biklen, 2007; Patton, 2002; Silverman, 2010; Yin, 2002).The data can be checked with multiple sources and data reliability is enhanced through this approach.

\section{Systems Analysis}

The inputs of the MRP model are identified through the systems analysis. These inputs are estimated room sales, product trees, inventory status records and ordering process, and information flow. In the information system that was developed in the study, three main elements are available in the form of database, model base and user interface.

The database involves all of the past and recorded information or the data created as a result of inquiries. In the scope of the study, the database involves information on estimated room sales, product trees, inventory, material consumptions and other information about the facility and the process. The model base, on the other hand, calculates material consumptions on a daily, weekly and monthly basis by dropping the relevant item from the inventory after each cleaning cycle. It also makes instant inventory and status updates.

The functioning of the system can be summarized as follows: after the reservation information is entered in the model, material requirement related to product trees is calculated based on the larger value by comparing with the forecasted sales figures. After the number of rooms to be cleaned is identified, an order is created by deciding whether the requirements will be supplied from the inventory or from outside according to the product tree. Simultaneously, the related items are dropped from the inventory, consumption amounts are calculated and the inventory is updated. Entries must be made lest the inventory falls out to shortage.

In the study, the ARIMA model was used as a means of estimating. The ARIMA (p, d, q) (P, D, Q) model, is the most famous model of the Box-Jenkins Models that are known as a combination of linear auto regressive (AR) and moving average (MA) models (Box, Jenkins, \& Reinsel, 2008; Montgomery, Jennings, \& Kulahc1, 2008). It is known that ARIMA differs from classical uni-variate time-series estimation models with not only in terms of creating equation or formula, but also crating models taking into account the probabilistic or random features of time-series as well as its success in making short-term estimations (Nahmias, 2009). For this reason, this model is preferred in the study. C \# software language was used in all coding and SQL 2008 was used as the database management system. StatGraphics 16.2 and Eviews 8 were used for forecasting.

\section{FINDINGS}

As a result of the systems analysis, the following deficiencies were detected:

- There is no reporting on the materials consumed. Therefore, the information related to materials used per-unit or in total during the day is not easily accessible by employees.

- Counts are not carried out by the cost control department on a monthly basis. All warehouses and department warehouses are counted in monthly counts. This situation prevents accessing the daily or weekly inventory information, or inventory information on a date range, instantly or when desired. Weekly material requirements are determined based on estimates rather than accurate calculations.

- Workforce planning is carried out according to actual or estimated reservations. This information is then passed from the front desk to the housekeeping department. Certain troubles can be experienced in this process.

- Forms are used to get the materials required for daily operations from the warehouses. These forms are not recorded in any database and are only filed to check, in the event of a possible mistake in the monthly reports.

The ARIMA (Auto regressive Moving Average) Model was utilized as the estimator in this study. Test statistics are summarized in Table 1. 
Table 1. ARIMA $(2,1,1)$ Test Statistics

\begin{tabular}{|l|l|l|l|l|}
\hline Parameter & Estimate & Stnd. Error & $t$ & P-value \\
\hline AR(1) & 0,597442 & 0,0559446 & 10,6792 & 0,000000 \\
\hline AR(2) & $-0,139499$ & 0,0548985 & $-2,54103$ & 0,011471 \\
\hline MA(1) & 0,929775 & 0,0219026 & 42,4504 & 0,000000 \\
\hline
\end{tabular}

When the results of Table 1 are examined, the t-statistic values are significant at $95 \%$ confidence interval. Thus, this model is accepted as a forecast tool in determining room sales in the information system. In the following section, the modules used in the software are introduced.

\section{Introduction of the Software Modules}

In this study, there are a total of three modules to be developed in the information system: Management, Operations and Reporting.

\section{The Management Module}

The management module is called as the Management Panel. The operations carried out with this module can be monitored through certain details such as \# rooms (cleaned), date, name of the staff and operation type on the Management Report under this module. The report image related to all operations of this monitor is presented in Figure 1.
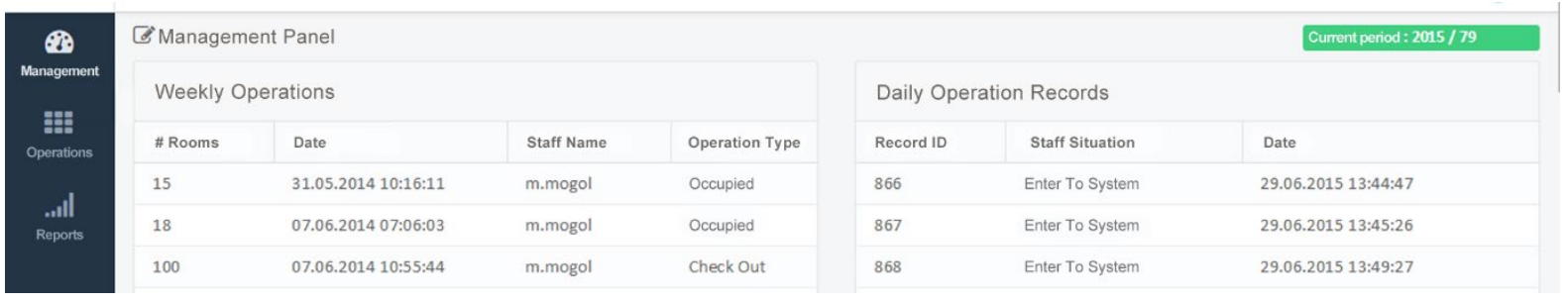

Figure 1. The Management Report

Periodic room operations can be monitored on the Management Report. This report is under the title of Weekly operations to the upper left side of the screen in Figure 1. This report includes operations based on date, personnel, operation type and number of rooms. The total number of operations is located on the upper right side of the report. All other operations that can be viewed on the management monitor are located under the title of Daily operations records to the lower-right portion of the screen.

Another operation that can be performed in this module is the calculation of estimated consumption based on reservation estimates. This report is summarized in Figure 2.
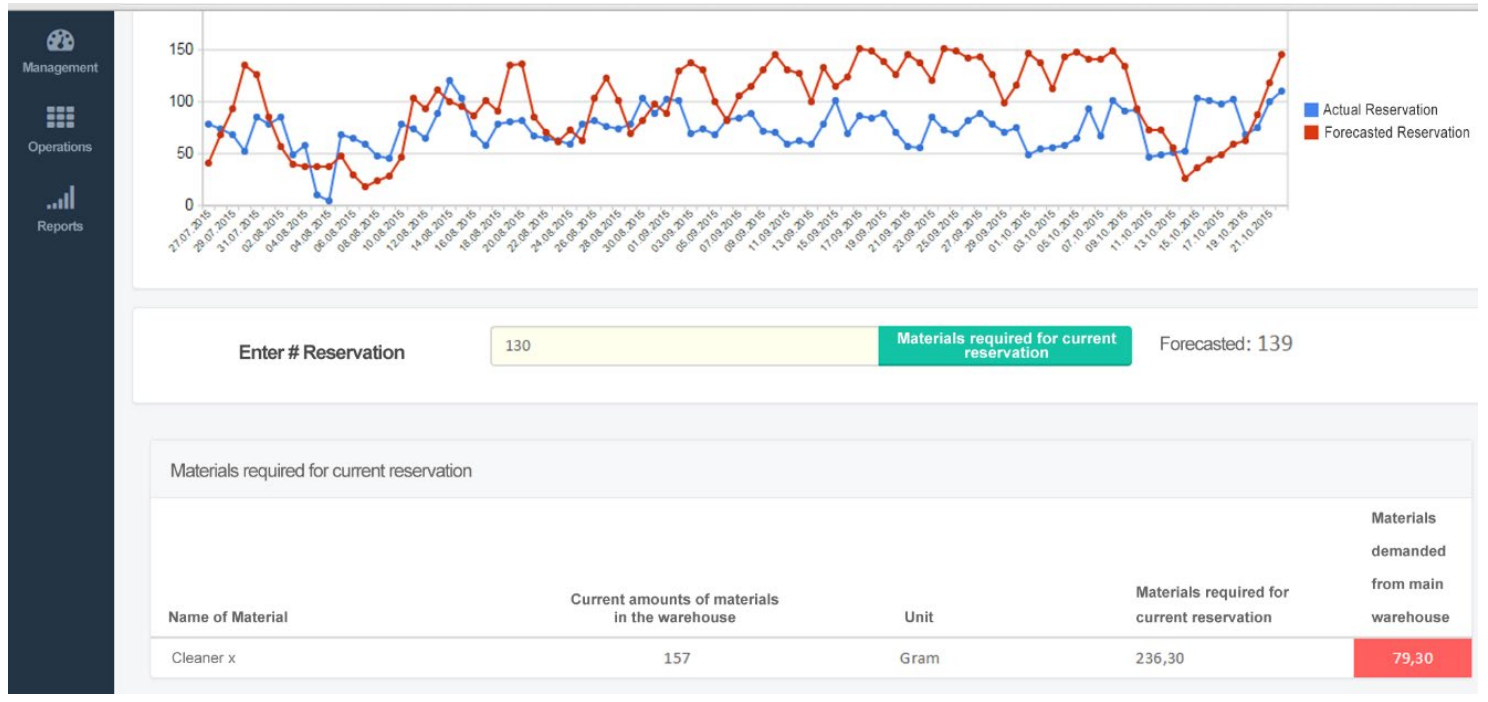

Figure 2. Calculation of Material Requirements Based on Reservations Report 
In the Figure 2, when the actual reservations are entered and the 'calculate' button is clicked, the Materials required for current reservation report which is located at the very bottom of the screen is created. In this report, the existing inventory is shown under the title of 'current amounts of materials in the warehouse'. The 'Materials required for current reservation' column indicates the amount of materials to be extracted from the main warehouse for each item of materials.

This report is used to determine the material requirement by comparing the past period's forecasted room sales with the reservations made at the end of the day, taking into account the safety stock. The graph above the report compares the past period sales with the estimated values. The graph involves weekly data and the estimation values are generated on a daily basis. In addition, the graphs are updated as new data is entered in the system.

\section{The Operations Module}

In the operations module, entries are made related to the performed operations. This module provides the user with the opportunity to identify any type of operations. Daily operation recording, inventory entry and ordering operations can be performed through the operations module.

The managers can monitor the periodically performed operations, the orders placed for these operations and the materials purchased as a whole. Hence, the managers can monitor employee performance as well as making projections regarding the financial resources allocated for the materials. Similarly, annual budgets are prepared depending on these figures.

\section{The Reports Module}

There are three basic reporting processes in this module: occupancy rates, inventory status and consumption reports.

Occupancy Rates: The first report gives occupancy rates. This report's screenshot is shown in Figure 3.

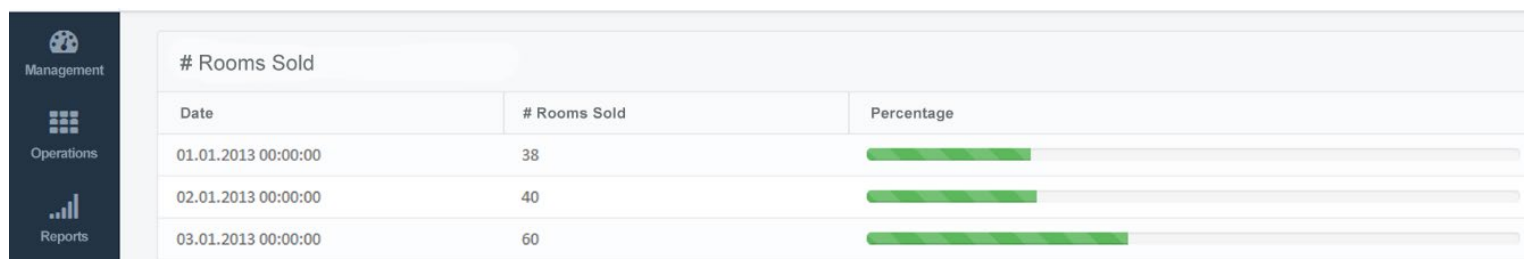

Figure 3 Occupancy Rates Report

Figure 3 shows the number of rooms sold by date. The occupancy rates are analyzed, periodical sales are estimated and the required materials can be calculated based on this estimation with this report. These reports are prepared by the hotel front desk and are also used to support and control the figures created thereof.

The Inventory Report: Another report in the reports module is the Inventory Status Report. This report's screenshot is shown in Figure 4.
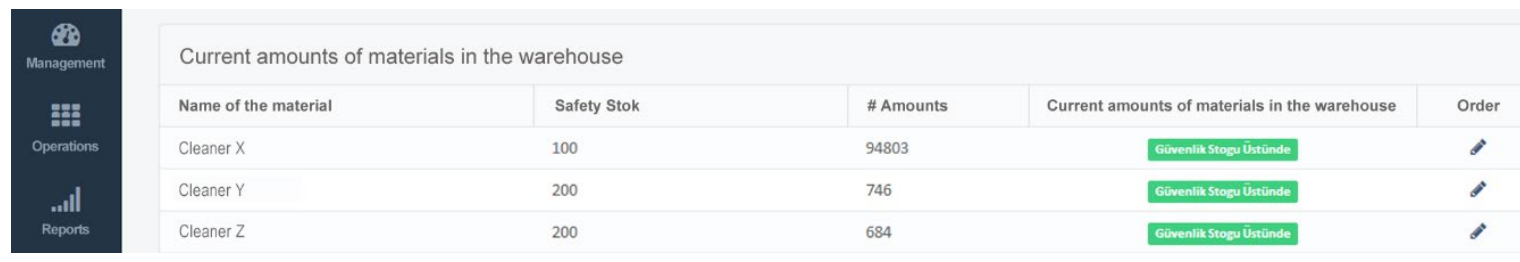

Figure 4. Inventory Status Report

The left side of the screen shows the material name, the safety stock and the amount of material available in the warehouse. On the right side, the bars in the status column show the general situation in reference to the safety stock (i.e., below the safety stock, above the safety stock, under $30 \%$ etc.). The bars on its right, on the other hand, visually (color) summarize the inventory status in reference to the safety stock. Green color indicates that the inventory is above the safety stock, yellow indicates that it is $30 \%$ below the safety stock and red indicates that it is under the safety stock. The 'Order' button is located at the right side of the screen. 
This button allows placing an order for each item of materials and directs the user to the ordering screen. Orders can be placed for each item of materials via this screen.

Consumptions Report: The last report in the reports module is the Consumption Report. This report is shown in Figure 5.

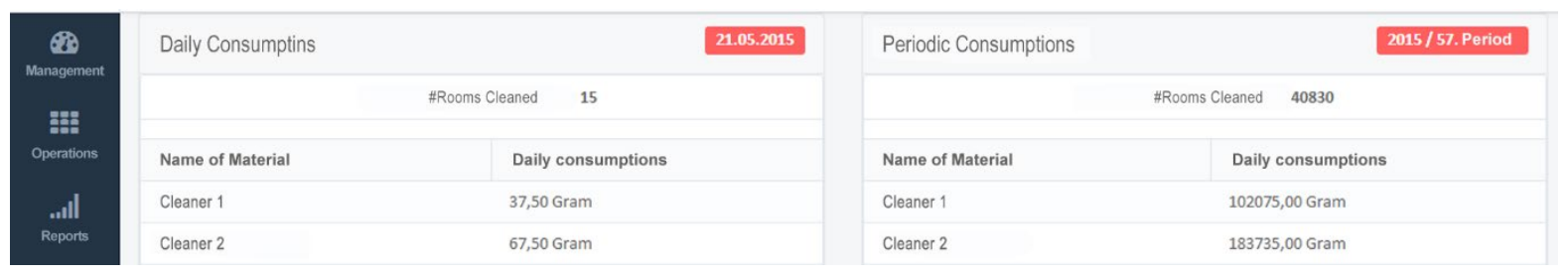

Figure 5. Consumption Report

In Figure 5, consumption is summarized in two different reports based on the material name. The daily consumption is seen on the left side of the screen and the total periodical (=weekly) consumption is seen on the right side of the same screen. In these reports, periodic consumption is calculated based on the total number of processes and according to the product trees, rather than making counts repetitively.

The advantage of this module for the managers is that it allows them to see daily and periodical material consumption. In the existing system, these calculations can be detected by the accounting department through monthly counts only. In other words, they have to wait until the end of the month to see the level of consumption. Furthermore, expenditures are expressed in an average figure. Since the module developed in the study is open to both the managers and employees, in other words it is open to the system monitoring, the employees should be careful about material consumption.

\section{CONCLUSION}

In the service sector, success is associated with a correct material planning. In this way, it will be possible to continue the operations smoothly, ensure customer satisfaction, minimize time loss keep employees working. Utilization of information systems in this field is inevitable considering the labor-intensive nature of the process and the working conditions.

With the information system introduced in the scope of this study, periodical planning can be performed to ensure that demand-dependent material is delivered to the hotel and the needs are met on time. In the hotels, where daily operations are intense, it is not possible to generate robust information by making the calculations related to material input, output, demand and usage by hand. With the software developed within the scope of this study, data control and analysis can be conducted much easily. The amounts of demand, inventory input and consumption can be calculated for each material. This makes it easier for decision makers to control materials periodically. By the same token, it is possible to make the month-end and year-end budget and actual figures close to each other.

The ordering report is available in the operations module. This report creates an order to be sent to the supplier. The housekeeping department sends its demands to the warehouse just as all departments. The warehouse decides either to buy the materials through the procurement department or to supply from the inventory. Currently, the requirements are informed to the procurement or warehouse either through forms or software in the hotels. With this report, the housekeeping department can control the materials it demands based on date and amount without needing any forms or other reporting. Thus, the year-end budget preparations and month-end budget current situation reports can be generated with more accurate figures and with a more realistic approach.

By means of this software, inventories are automatically updated after the inventory entries of procured materials are made in order to access inventory status information. In the software, the previous period inventories are periodically transferred and the consumed amounts are automatically dropped after the number of operations performed is entered. Thus, it is possible to see the inventories instantly. In this way, a more trackable inventory management system is established and excess material procurement is avoided. In addition, stocking of excess material is prevented and inventory costs are minimized. 
The software estimates the daily number of rooms to be cleaned through its own forecast tool without estimated room sales figures received from the front desk. Thus, the material procurement process is planned in advance. In the software, the order quantity is calculated by taking the difference between the current inventory and the required inventory information (see the current inventory report under the management monitor). Thus, the users' need to calculate the amount to be ordered for each material item is eliminated.

The software developed in the study is web based and has a mobile application. Thus, the decision maker can access the system from any media with Internet connection to manage the operations. With the mobile application of the software, access to the system via smart phones has been made available.

The software has been tested in two five star international chain hotels. One of the cost items of the hotels is the materials. With the very software, the required materials can be determined in advance by making weekly planning. Thus, no material procurement is made before the relevant term and the increase in the amount of inventory and storage costs in relation to this can be avoided.

This MRP software has been developed taking into consideration the features of hotels with various functioning structures. This software can be customized through the identification of both the works to be done and the materials to be used in the cleaning process by the hotel management. In other words, the software can be tailored according to demands and needs of the customer (hotel). Thus, a MRP software that can be easily used and understood by hotel administrations has been developed in the study.

Another feature of this software is that it can be easily used in many product and service providing companies, in addition to hotels, after necessary modifications are applied.

\section{DISCUSSION}

It has been observed in the study that some departments of the hotels do not use software in the areas of inventory management, ordering and employee performance monitoring. This study, attempts to bridge the gap in this field especially by facilitating the monitoring of these processes in an integrated manner.

The software developed in this study is intended to control the relevant processes of the hotels. It is considered that the study will contribute to the literature since, although there are many studies on MRP, there is a limited number of studies on the services sector and no studies especially on hotels.

Despite the fact that there are a lot of MRP software, an MRP software for hotels was developed for the first time in this study. For this reason, it is thought that the study will contribute to the business world in practice.

\section{IMPLICATIONS FOR FUTURE STUDIES}

This software has been designed in a way to be used in other sectors as well. The issue to be considered here is the similarity of the processes. In this information system, the customer and supplier leg is not taken into consideration. With certain additions to be implemented, this software can be rendered compatible with new business models. Thus, the company will not have to monitor the inventory apart from its short-term needs and the logistics firm will be able to make this inventory on behalf of the company.

\section{REFERENCES}

Andersson, H., Axs ̈̈Ter, S., \& JÖNsson, H. (1981). Hierarchical material requirements planning. International Journal of Production Research, 19(1), 45-57. doi:10.1080/00207548108956628

Bai, X., Davis, J. S., Kanet, J. J., Cantrell, S., \& Patterson, J. W. (2002). Schedule instability, service level and cost in a material requirements planning system. International Journal of Production Research, 40(7), 1725-1758. doi:10.1080/00207540110119973

Bogdan, B., \& Biklen, S. K. (2007). Qualitative Research for Education: an Introduction to Theories and Methods. Boston: Pearson.

Box, G. E. P., Jenkins, G. M., \& Reinsel, G. C. (2008). Time Series Analysis: Forecasting and Control. N.J.: Wiley.

Gomm, R., Hammersley, M., \& Foster, P. (2000). Case Study Method. London: Sage. 
Huarng, F. (1998). Hospital Material Management in Taiwan: A Survey. Hospital Material Management Quarterly, 19(4), 71-81.

Johnston, W. J., Leach, M. P., \& Liu, A. H. (1999). Theory Testing Using Case Studies in Business-to-Business Research. Industrial Marketing Management, 28(3), 201-213. doi:https://doi.org/10.1016/S0019$\underline{8501(98) 00040-6}$

Lee, T. S., \& Adam, E. E. (1986). Forecasting Error Evaluation in Material Requirements Planning (MRP) Production-Inventory Systems. Management Science, 32(9), 1186-1205.

Lin, N. P., \& Krajewski, L. (1992). A Model for Master Production Scheduling Environments", . Decision Sciences, 23(4), 839-861.

Montgomery, D. C., Jennings, C. L., \& Kulahc1, M. (2008). Introduction to Time Series Analysis and Forecasting. N.J.: Wiley.

Mula, J., Poler, R., \& Garcia-Sabater, J. P. (2008). Capacity and material requirement planning modelling by comparing deterministic and fuzzy models. International Journal of Production Research, 46(20), 55895606. doi:10.1080/00207540701413912

Mula, J., Poler, R., \& Garcia, J. P. (2006). MRP with flexible constraints: A fuzzy mathematical programming approach. Fuzzy Sets and Systems, 157(1), 74-97. doi:https://doi.org/10.1016/j.fss.2005.05.045

Nahmias, S. (2009). Production and Operation Analysis. Singapore: McGraw Hill.

O'Neill, L., Murphy, M., Gray, D., \& Stoner, T. (2001). An MRP System for Surgical Linen Management. Journal of Medical Systems, 25(1), 63-71.

Patton, M. Q. (2002). Qualitative Research and Evaluation Methods. California: Sage.

Sam, T. (1990). Material Requirements Planning: A Better Way to Plan Material. Material Management Quarterly, 12(1), 30-33.

Seale, C., Gobo, G., Gubrium, J. F., \& Silverman, D. (2004). Qualitative Research Practice. London: Sage.

Segerstedt, A. (1996). A capacity-constrained multi-level inventory and production control problem. International Journal of Production Economics, 45(1), 449-461. doi:https://doi.org/10.1016/0925$\underline{5273(96) 00017-5}$

Showalter, M. J. (1987). Are Manufacturing Inventory Concepts Applicable for Material Management in Hospitals. Hospital Material Management Quarterly, 8(4), 70-76.

Silverman, D. (2010). Doing Qualitative Research: a Practical Handbook. Los Angeles: Sage.

Stevenson, W. J. (2009). Operations Management. Boston: McGraw Hill.

Turban, E., \& Volonino, L. (2013). Information Technology for Management. Asia: John Wiley\&Sons.

Xie, J., Lee, T. S., \& Zhao, X. (2004). Impact of forecasting error on the performance of capacitated multi-item production systems. Computers $\mathcal{E} \quad$ Industrial Engineering, 46(2), 205-219. doi:https://doi.org/10.1016/j.cie.2003.12.020

Yeung, J. H. Y., Wong, W. C. K., \& Ma, L. (1998). Parameters affecting the effectiveness of MRP systems: A review. International Journal of Production Research, 36(2), 313-332. doi:10.1080/002075498193750

Yin, R. K. (2002). Applications of Case Study Research (2. ed.). CA: Sage. 